\title{
UJI TINGKAT KOMPATIBILITAS DAN UMUR MEKAR BUNGA PADA PERSILANGAN INTERGENERIK ANGGREK Vanda sp DAN Phalaenopsis sp
}

\author{
Sri Hartati ${ }^{1 *}$, Ongko Cahyono ${ }^{2)}$ dan Nunik Puji Lestari ${ }^{1)}$ \\ ${ }^{1)}$ Program Studi Agroteknologi, Fakultas Pertanian, Universitas Sebelas Maret \\ ${ }^{2)}$ Fakultas Pertanian Universitas Tunas Pembangunan Surakarta \\ *Corresponding author: srihartati57@staff.uns.ac.id
}

\begin{abstract}
The study aims to determine the effect of compatibility level to the intergeneric crossing ability and the age of the flower blooming of Vanda sp and Phalaenopsis sp. Research was conducted at a screen house and Plant Breeding Laboratory of Faculty of Agriculture, Sebelas Maret University. Crossing is done by inserting pollen of male parent to the stigma of the female parent which were selected based on a predetermined number of crosses. The observations included: percentage of successful crosses, time of fruit formation, durability of hanging fruit, the percentage of fruit ready for harvest, the percentage of the fallen fruit, and the level of compatibility. The study concluded that the intergeneric cross between Vanda sp and Phalaenopsis sp can be done until the age of 3 weeks after the flowers bloom. The fruit begins to form at the age of 6-12 day after crosses (DAC) and can be harvested after reaching the age of about three months. The intergeneric cross between Vanda sp and Phalaenopsis sp is compatible, because this was capable of producing the fruit of more than $60 \%$.
\end{abstract}

Keywords: Crossing; Intergeneric; Orchids; Phalaenopsis sp; Vanda sp

Cite this as: Hartati, S., Cahyono, O., \& Lestari, N. 2017. Uji Tingkat Kompatibilitas dan Umur Mekar Bunga pada Persilangan Intergenerik Anggrek Vanda sp dan Phalaenopsis sp. Caraka Tani: Journal of Sustainable Agriculture. 32(1), 24-28. doi: http://dx.doi.org/10.20961/carakatani.v32i1.15924

\section{PENDAHULUAN}

Anggrek merupakan tanaman hias yang sangat prospektif dan mempunyai nilai ekonomis tinggi, karena bentuk dan warna bunga menarik serta mempunyai daya tahan lama. Anggrek sebagai salah satu jenis tanaman hias dengan segala keunikan yang memukau telah menarik perhatian para penggemar tanaman hias baik dari dalam maupun luar negeri (Parnata, 2005).

Keluarga anggrek (Orchidaceae) merupakan salah satu familia tumbuhan berbunga terbanyak di dunia mencakup spesies alami dan hasil persilangan (Xiang dan Hong, 2003). Untuk menambah keragaman genetik baru perlu dilakukan persilangan dengan jenis lain

Ketersediaan anggrek Vanda sp masih terbatas dan sulit ditemukan di pasaran sehingga nilai jual menjadi lebih tinggi dibandingkan jenis anggrek lain. Bunga Vanda sp berukuran besar dan bulat serta sangat beragam sehingga sangat cocok bila digunakan sebagai bahan induk silangan. Menurut Bety et al. (2004) dengan adanya peluang mengembangkan anggrek jenis-jenis baru dari
Vanda sp. Vanda sp dan Phalaenopsis sp merupakan genus anggrek yang berperan dalam persilangan anggrek. Selain dari hibrid antar spesies, kelompok Vanda sp dan Phalaenopsis sp juga dapat dibuat persilangan antar genus. Setiawan (2005) menjelaskan bahwa penggemar anggrek Vanda sp cukup banyak, tetapi penyediaan terbatas dan harga cukup mahal, sangat indah dengan bentuk bunga bulat dan kombinasi warna serasi. Oleh karena itu, sangat cocok sebagai bahan induk persilangan.

Melalui kegiatan persilangan Vanda sp dengan Phalaenopsis sp ini akan diperoleh tingkat kompatibilitas di antara kedua tetua terpilih. Selain itu, juga akan diketahui seberapa besar pengaruh persilangan intergenerik dan umur mekar bunga terhadap kemampuan silang anggrek Vanda sp dengan Phalaenopsis sp sampai tahap pembentukan buah.

\section{METODE PENELITIAN}

Persilangan dilakukan pagi hari pukul 07.00 8.00 di screenhouse Jalan Jawa Nomor 15 Solo. 
Bahan: tanaman anggrek yang telah berbunga yaitu Vanda Dr. Anek "FCC" dengan bunga merah cerah/pink, dan Phalaenopsis Mushasino berwarna putih, Phalaenopsis Shalu Porket (bunga kuning berbintik merah di tengah); pupuk OSF $2 \mathrm{cc} / \mathrm{l}$; Vitamin B1 $2 \mathrm{cc} / \mathrm{l}$; dan Fungisida Dithane $451 \mathrm{~g} / 1$. Alat-alat: tusuk gigi, benang, kertas penanda, kamera, dan alat tulis.
Metode penelitian: persilangan pada 3 individu sebagai ulangan, dengan metode sebagai berikut: crossing (Vanda Dr. Anek "FCC $x$ त Phalaenopsis Mushasino ((+Vanda Dr. Anek "FCC ${ }^{\lambda}$ Phalaenopsis Shalu Porket) Tiny), yaitu polinia ditransfer ke dalam stigma antara dua bunga yang berbeda dan berasal dari dua individu tanaman. Persilangan dilakukan 18 kali dengan nomor persilangan sebagai berikut:

Tabel 1. Nomor dan Jenis Tetua dalam Persilangan Vanda $\mathrm{sp}\rangle\langle$ Phalaeopsis $\mathrm{sp}$

\begin{tabular}{|c|c|c|}
\hline $\begin{array}{l}\text { Nomor } \\
\text { Persilangan }\end{array}$ & Jenis tetua persilangan & $\begin{array}{l}\text { Umur mekar bunga } \\
\text { (minggu setelah } \\
\text { mekar/MSM) }\end{array}$ \\
\hline 1. & Vanda Dr. Anek "FCC" >< Phalaenopsis Mushasino Tiny & 1 \\
\hline 2. & Vanda Dr. Anek "FCC" $><$ Phalaenopsis Mushasino Tiny & 1 \\
\hline 3. & Vanda Dr. Anek "FCC" $><$ Phalaenopsis Mushasino Tiny & 1 \\
\hline 4. & Vanda Dr. Anek "FCC" $><$ Phalaenopsis Mushasino Tiny & 2 \\
\hline 5. & Vanda Dr. Anek "FCC" >< Phalaenopsis Mushasino Tiny & 2 \\
\hline 6. & Vanda Dr. Anek "FCC" $><$ Phalaenopsis Mushasino Tiny & 2 \\
\hline 7. & Vanda Dr. Anek "FCC" $><$ Phalaenopsis Mushasino Tiny & 3 \\
\hline 8. & Vanda Dr. Anek "FCC" $><$ Phalaenopsis Mushasino Tiny & 3 \\
\hline 9. & Vanda Dr. Anek "FCC" >< Phalaenopsis Mushasino Tiny & 3 \\
\hline 10. & Vanda Dr. Anek "FCC" >< Phalaenopsis Shalu Porket & 1 \\
\hline 11. & Vanda Dr. Anek "FCC" $><$ Phalaenopsis Shalu Porket & 1 \\
\hline 12. & Vanda Dr. Anek "FCC" $><$ Phalaenopsis Shalu Porket & 1 \\
\hline 13. & Vanda Dr. Anek "FCC" $><$ Phalaenopsis Shalu Porket & 2 \\
\hline 14. & Vanda Dr. Anek "FCC" $><$ Phalaenopsis Shalu Porket & 2 \\
\hline 15. & Vanda Dr. Anek "FCC" $><$ Phalaenopsis Shalu Porket & 2 \\
\hline 16. & Vanda Dr. Anek "FCC" >< Phalaenopsis Shalu Porket & 3 \\
\hline 17. & Vanda Dr. Anek "FCC" >< Phalaenopsis Shalu Porket & 3 \\
\hline 18. & Vanda Dr. Anek "FCC" >< Phalaenopsis Shalu Porket & 3 \\
\hline
\end{tabular}

Variabel Pengamatan: keberhasilan persilangan (\%), saat terbentuk buah, daya tahan buah menggantung, jumlah buah siap panen (\%), jumlah buah rontok (\%), tingkat kompatibilitas,. Tingkat kompatibilitas berdasarkan klasifikasi persilangan (Hartati, 2015) yaitu: 1.) kompatibel penuh jika persilangan menghasilkan buah di atas $60 \%, 2$.) kompatibel sebagian, jika buah yang dihasilkan antara 30 - 60\%, dan 3.) inkompatibel penuh jika hasil persilangan di bawah $30 \%$. Analisis Data: Data yang diperoleh dianalisis menggunakan analisis deskriptif.

\section{HASIL DAN PEMBAHASAN}

\section{Persentase Keberhasilan Persilangan}

Persentase keberhasilan persilangan ditentukan dengan cara menghitung buah terbentuk dari jumlah keseluruhan bunga yang disilangkan. Tabel 2 menunjukkan bahwa dari 18 persilangan berhasil 11 persilangan $(61,11 \%)$.

Keberhasilan penyerbukan terjadi ketika pollinarium dapat dimasukkan ke rostellum tersebut (Chaturvedi dan Shonali, 2010). Persilangan dapat dikatakan berhasil karena bunga anggrek menunjukkan bakal buah terlihat masih segar, berwarna hijau, dan pada bagian pangkal tangkai bunga terlihat membesar. Beberapa hari kemudian, bagian perhiasan bunga akan terlihat semakin layu.

Persilangan antara Phalaenopsis sp dan Vanda tricolor bersifat kompatibel, jika Vanda tricolor sebagai induk betina (Hartati, 2010). Metode pemuliaan konvensional dengan menggunakan persilangan, seperti intraspesifik dan interspesifik spesies anggrek, adalah cara umum untuk membuat varietas baru (Semiarti et al., 2007). 
Tabel 2. Persentase Keberhasilan Persilangan Vanda $\mathrm{sp}><$ Phalaenopsis $\mathrm{sp}$

\begin{tabular}{cc}
\hline Nomor Persilangan & Keberhasilan Persilangan \\
\hline 1. & + \\
2. & - \\
3. & - \\
4. & + \\
5. & + \\
6. & + \\
7. & + \\
8. & + \\
9. & + \\
10. & - \\
11. & - \\
12. & + \\
13. & + \\
14. & - \\
15. & + \\
16. & - \\
17. & - \\
18. & + \\
\hline Jumlah berhasil & 11 \\
\hline Persentase & \\
keberhasilan & 61,11 \\
persilangan $(\%)$ &
\end{tabular}

Keterangan: $+=$ berhasil

$$
\text { - = gagal }
$$

\section{Saat Terbentuk Buah}

Pengamatan saat terbentuk buah dimulai pada 3 - 4 HSP (Hari Setelah Persilangan), karena menurut Sutiyoso dan Sarwono (2002) keberhasilan suatu persilangan dapat diamati pada 3 - 4 hari setelah persilangan. Waktu pembentukan buah dari setiap nomor persilangan berbeda. Hal ini diduga karena setiap bunga memiliki kemampuan silang dan merespon persilangan yang berbeda. Kemampuan silang dan merespon persilangan ini diduga dipengaruhi oleh ketersediaan nutrisi setiap bunga. Nutrisi cukup membuat bunga dapat menyilang dan merespon persilangan lebih cepat dibandingkan bunga dengan nutrisi=kurang.

Jumlah kuntum bunga yang disilangkan dalam satu tangkai diduga dapat mempengaruhi kecepatan buah terbentuk. Semakin banyak kuntum bunga dalam satu tangkai yang disilangkan, maka nutrisi yang dibutuhkan untuk pembentukan buah semakin banyak, sementara persediaan nutrisi tanaman terkadang kurang mencukupi. Oleh karena itu nutrisi perlu ditingkatkan agar pembentukan buah dapat terjadi.

Tabel 3. Rata-rata saat terbentuk Buah, Daya Tahan Buah Menggantung, Buah Siap Panen dan Rontok Hasil Persilangan Vanda $\mathrm{sp}\rangle<$ Phalaenopsis $\mathrm{sp}$

\begin{tabular}{|c|c|c|c|c|}
\hline $\begin{array}{c}\text { Nomor } \\
\text { persilangan }\end{array}$ & $\begin{array}{c}\text { Saat terbentuk } \\
\text { buah (HSP) }\end{array}$ & $\begin{array}{c}\text { Daya tahan buah } \\
\text { menggantung (HSB) }\end{array}$ & Kondisi buah & Keterangan \\
\hline 1 & 9 & 98 & $\mathrm{P}$ & \\
\hline 4. & 7 & 100 & $\mathrm{P}$ & \\
\hline 5. & 7 & 100 & $\mathrm{P}$ & HSP : Hari Setelah \\
\hline 6. & 7 & 92 & $\mathrm{P}$ & Persilangan \\
\hline 7. & 12 & 81 & $\mathrm{P}$ & HSB : Hari Setelah \\
\hline 8. & 12 & 53 & $\mathrm{R}$ & Pembuahan \\
\hline 9. & 12 & 45 & $\mathrm{R}$ & : buah siap panen \\
\hline 12. & 6 & 81 & $\mathrm{P}$ & \\
\hline 13. & 10 & 4 & $\mathrm{R}$ & : buah rontok \\
\hline 15. & 10 & 4 & $\mathrm{R}$ & \\
\hline 18. & 10 & 74 & $\mathrm{P}$ & \\
\hline Jumlah & 102 & 734 & $\begin{array}{l}\mathrm{P}: 7 \\
\mathrm{R}: 4\end{array}$ & \\
\hline Rata-rata & $9,27 \approx 10$ & $66,73 \approx 67$ & $\begin{array}{l}\mathrm{P}: 63,7 \% \\
\mathrm{R}: 36,3 \%\end{array}$ & \\
\hline
\end{tabular}

Berdasarkan tabel 3 menunjukkan bahwa hasil persilangan Vanda $s p><$ Phalaenopsis sp ratarata buah akan terbentuk pada 6 - 12 HSP. Buah terbentuk tercepat diperoleh pada persilangan nomor 12 yaitu Vanda Dr. Anek "FCC" 1 MSM $><$ Phalaenopsis Shalu Porket, sedangkan paling 
lama pada persilangan nomor 7,8 , dan 9 yaitu persilangan Vanda Dr. Anek "FCC" 3 MSM >< Phalaenopsis Mushasino Tiny.

\section{Daya Tahan Buah Menggantung}

Buah akan terbentuk pada tangkai bunga tepat di belakang mahkota bunga. Umur buah berbedabeda karena setiap buah memiliki daya tahan menggantung/kemampuan hidup yang berbeda. Buah ada yang bertahan lama menggantung hingga panen, namun ada juga yang tidak dapat tumbuh terus/tidak sampai masak (rontok lebih dahulu).

Seperti yang ditunjukkan pada tabel 3 , buah yang terbentuk dari hasil persilangan anggrek Vanda $s p><$ Phalaenopsis sp dengan berbagai nomor persilangan memiliki daya tahan menggantung berbeda-beda, ada yang dapat bertahan hingga panen dan ada pula yang rontok sebelum dipanen. Dari tabel 3 tersebut dapat diketahui bahwa daya tahan menggantung buah anggrek paling lama terdapat pada persilangan nomor 4 dan 5, yang masing-masing merupakan buah hasil persilangan Vanda Dr. Anek "FCC" 2 MSM >< Phalaenopsis Mushasino Tiny, yaitu selama 100 HSB (Hari Setelah Pembuahan). Untuk daya tahan buah menggantung terendah didapat pada persilangan nomor 13 dan 15, merupakan persilangan antara Vanda Dr. Anek "FCC" 2 MSM $><$ Phalaenopsis Shalu Porket, dengan waktu hanya 4 HSB.

Perbedaan daya tahan buah menggantung ini oleh faktor luar dan fisiologis tanaman anggrek itu. Menurut Darjanto dan Satifah (1990) embrio dan endosperm dapat berhenti tumbuh karena terjadi kombinasi tertentu pada tetua indukan, hal ini mengakibatkan buah yang dihasilkan tidak normal sehingga rontok sebelum matang. Selain faktor tersebut, inkompatibilitas sering juga menjadi kendala dalam persilangan antargenus/marga.

\section{Jumlah Buah Siap Panen dan Buah Rontok}

Tidak semua buah yang terbentuk dapat dipanen, karena rontok sebelumnya. Penyebab kerontokan buah sebelum panen antara lain embrio dan endosperm berhenti tumbuh sehingga tidak normal, tidak kuat dan selanjutnya lekas mati kemudian rontok. Berdasarkan tabel 3 dari 11 buah yang terbentuk, 4 buah rontok sebelum panen. Pada persilangan Vanda Dr. Anek "FCC" 1 dan 2 MSM $><$ Phalaenopsis Mushasino Tiny nomor persilangan $1,4,5,6$, dan 7 serta persilangan Vanda Dr. Anek "FCC" 1 dan 3 MSM >< Phalaenopsis Shalu Porket nomor persilangan 12 dan 18 menghasilkan buah yang siap panen. Pada persilangan nomor 8 dan 9 , yaitu antara Vanda Dr. Anek "FCC" 3 MSM >< Phalaenopsis Mushasino Tiny gagal menuju panen karena rontok.

Tremblay et al. (2005) dalam Cheng et al. (2009) menunjukkan kegagalan membentuk buah apabila penyerbukan dilakukan pada bunga yang sama (autogamy) maupun lain bunga pada tanaman yang sama (geitonogamy), hal ini karena ketidakcocokan pada tanaman Orchidaceae.

Tingkat ketahanan hidup buah diduga dipengaruhi oleh jumlah bunga yang disilangkan dalam satu tangkai. Apabila dalam satu tangkai terlalu banyak bunga yang disilangkan maka tanaman tidak akan mampu memberikan suplai makanan cukup untuk perkembangan buah. Penelitian Sivanaswari et al. (2011) menunjukkan bahwa umur masak buah pada persilangan beberapa anggrek Aerides spp dengan secara crossing (persilangan) Aerides odorata sebagai induk betina menghasilkan umur masak buah berkisar 0 - 179 hari.

\section{Tingkat Kompatibilitas}

Tabel 4. Tingkat Kompatibilitas Persilangan Vanda $\mathrm{sp}><$ Phalaenopsis $\mathrm{sp}$

\begin{tabular}{ccc}
\hline $\begin{array}{c}\text { Nomor } \\
\text { persilangan }\end{array}$ & $\begin{array}{c}\text { Buah } \\
\text { terbentuk }\end{array}$ & Keterangan \\
\hline 1. & + & \\
2. & - & \\
3. & - & \\
4. & + & \\
5. & + & \\
6. & + & buah dapat \\
7. & + & terbentuk \\
8. & + & terbentuk \\
9. & + & \\
10. & - & - \\
11. & - & \\
12. & + & \\
13. & + & \\
14. & - & \\
15. & + & \\
16. & - & \\
17. & - & \\
18. & + & \\
\hline Jumlah buah & 11 & \\
terbentuk & \multicolumn{2}{|c}{ (kompatibel) } \\
\hline Persentase $(\%)$ & 61,11 & \\
\hline
\end{tabular}


Daya kompatibilitas adalah persentase kemampuan membentuk buah, sedangkan daya fertilitas adalah kemampuan fertilisasi (Widiastoety, 2003). Inkompatibilitas terjadi oleh ketidakmampuan organ jantan dan betina menghasilkan biji seksual akibat faktor fisiologi, serta tidak mampu menghasilkan pollen tube dengan cepat sampai ke ovul. Inkompatibilitas pada kombinasi persilangan disebabkan oleh ketidaksesuaian antara organ jantan dengan betina. Ketidaksesuaian ini dikendalikan oleh faktor lingkungan, genetik, dan fisiologis (Poespodarsono, 1998 dalam Widhiastuti, 2006).

Tabel 4 menunjukkan bahwa antara tetua jantan dan tetua betina dalam persilangan ini memiliki kemampuan silang yang baik karena dapat membentuk buah lebih dari $61,11 \%$. Klasifikasi kompatibilitas menyatakan bahwa jika dari keseluruhan persilangan terdapat lebih dari $60 \%$ buah berhasil terbentuk, maka kedua tetua tersebut dapat dikatakan kompatibel penuh (Hartati, 2015)

\section{KESIMPULAN}

Persilangan anggrek Vanda sp dengan Phalaenopsis sp dapat dilakukan sampai waktu 3 minggu setelah bunga mekar. Buah anggrek hasil persilangan Vanda $\mathrm{sp}><$ Phalaenopsis sp mampu dipanen setelah mencapai umur \pm 3 bulan. Antara organ jantan dan betina terjadi kesesuaian (kompatibel penuh) dengan persentase buah terbentuk $>60 \%$.

\section{DAFTAR PUSTAKA}

Bety, Y.A. 2004. Karakter KegenJahan Beberapa Populasi F1 Anggrek Vanda. Prosiding Seminar Nasional Florikultura, Bogor, 4-5 Agustus: 125-129.

Chaturvedi, S.K., \& Chaturvedi, S. 2010. Biotic Pollination in Aerides odorata Lour (Orchidaceae). The International Journal of Plant Reproduction Biology. 2(1), 45-49.

Cheng, J., Shi, J., Shangguan, F.Z., Dafni, A., Deng, Z.H., \& Luo, Y.B. 2009. The pollination of a self-incompatible, food-mimic orchid, Coelogyne fimbriata (Orchidaceae), by female Vespula wasps. Journal Annal of Botany. 104(3), 565-571.
Darjanto, \& Satifah, S. 1990. Pengetahuan Dasar Biologi Bunga dan Teknik Penyerbukan Silang Buatan. Jakarta: PT Gramedia.

Hartati, S. 2010. The intergeneric crossing of Phalaenopsis sp and Vanda tricolor. Jurnal of Biotechnologi and Biodiversity. 1(1), 26-30.

Hartati, S. 2015. Analisis Keragaman Genetik Tetua dan Hasil Persilangan Anggrek Hitam (Coelogyne pandurata Lindl.) (Disertasi).

Parnata, A.S. 2005. Panduan Budidaya dan Perawatan Anggrek. Agromedia Pustaka: Jakarta.

Semiarti, E., Indrianto, A., Purwantoro, A., Isminingsih, S., Suseno, N., Ishikawa, T., Yoshioka, Y., Machida, Y., \& Machida, C. $2007 . \quad$ Agrobacterium-mediated transformation of the wild orchid spesies Phalaenopsis amabilis. Plant Biotechnology. 24(2), 265-272.

Setiawan, H. 2005. Usaha Pembesaran Anggrek. Jakarta: Penebar Swadaya.

Sivanaswari, Chalaparmal, Thohirah, L.A., Fadelah, A.A., \& Abdullah, N.A.P. 2011. Hybridization of several Aerides species and in vitro germination of its hybrid. African Journal of Biotechnology. 10(53), 1086410870.

Sutiyoso, Y., \& Sarwono. 2002. Merawat Anggrek. Jakarta: Penebar Swadaya.

Widhiastuti, M. 2006. Pengaruh Persilangan Intergenerik Dan Umur Mekar Bunga Terhadap Kemampuan Silang Anggrek Doritis pulcherrima var. Champoenensis Dengan Phalaenopsis sp. Skripsi S1 Fakultas Pertanian UNS. Surakarta.

Widiastoety, D. 2003. Menghasilkan Anggrek Silangan. Penebar Swadaya. Jakarta.

Xiang, N., \& Hong, Y. 2003. Genetic Analysis of Tropical Orchid Hybrid (Dendrobium) With Flourescence Amplified Fragment Length Polymorphisme (AFLP). Journal American Society Hortikultura Science. 128(5), 731-735. 